\title{
A CASE REPORT ON PLEOMORPHIC ADENOMA OF SUBMANDIBULAR GLAND
}

Farrukh Hassan, Anup Kumar, Brajesh Mishra, Sandeep Agarwal, Rakesh Kumar Tarun,

1. Assistant Professor. Department of General Surgery, Rajendra Institute of Medical Sciences, Ranchi,

2. Assistant Professor. Department of Radiotherapy, Rajendra Institute of Medical Sciences, Ranchi,

3. Consultant Pulmonologist, SJHRC, Ranchi.

4. Junior Resident, Department of General Surgery, Rajendra Institute of Medical Sciences, Ranchi,

5. Junior Resident, Department of General Surgery, Rajendra Institute of Medical Sciences, Ranchi,

\section{CORRESPONDING AUTHOR:}

Dr. Farrukh Hassan,

Sattar Colony, Bariatu,

Ranchi-234009, Jharkhand.

E-mail: hassanfarrukh@rediffmail.com

ABSTRACT: Pleomorphic adenoma of submandibular gland is a very rare condition compared to that of parotid. We are here discussing a case of the same in a 40yrs old male with clinical, operative, and histological findings .

KEY WORDS:-Pleomorphic adenoma, Submandibular gland

CASE REPORT: A 40 year old male presented to our out-patient department with a painless huge swelling on right side of neck since 15 years. The lump was extending from right lower cheek to just above clavicle and from midline to angle of mandible. It was about $10 \mathrm{~cm}$ in length and $7 \mathrm{~cm}$ in breadth. The lump was of lemon size to begin with and has slowly grown to present dimensions. Size of the lump has no relation with chewing. On examination, the lump had variegated consistency and was not fixed either to skin or deeper structures. There was no regional lymphadenopathy. Head and neck examination otherwise was normal and so was general examination.

Fine needle aspiration cytological examination of swelling showed it to be pleomorphic adenoma of submandibular gland. A suprahyoid neck dissection was done under general anaesthesia with preservation of marginal mandibular, lingual and hypoglossal nerves. No cervical lymphadenopathy was detected during dissection as well.

Histopathological examination of the biopsy specimen showed salivary gland tissue with well encapsulated lesion composed of admixture of epithelial and stromal elements. There was stromal predominance with mainly fibroblast. The epithelial cells were arranged in tubular and trabecular patterns with prominent myoepithelial components, these were embedded in dense fibrous stroma which also showed chondromyxoid areas resembling cartilage. No atypia was reported. Histology was consistent with pleomorphic adenoma.

DISCUSSION: Benign mixed tumour (pleomorphic adenoma) is the most common neoplasm of salivary gland. It is most frequent in women in $4^{\text {th }}$ decade of life, but it can be seen in children and elderly of either sex. It is ten times more common in parotid than in submaxillary gland.

Grossly the tumour forms a rubbery, resilient mass with a bosselated surface and may grow to large size. The consistency depends on relative amount of epithelial cells and stroma and type of latter. 
Microscopically, typical mixed tumour has biphasic appearance resulting from intimate admixture of epithelium and stroma. Most of the epithelial component is of glandular nature. Stroma may have non-specific fibromyxoid appearance, however areas of clear cut cartilaginous differentiation are usually found. Benign mixed tumour is frequently misdiagnosed as carcinoma by the novice in pathology due to its extreme cellularity, scattered bizarre tumour cells, partial penetration of capsule and occasional occurrence of clusters of tumour cells in vascular lamina. ${ }^{3}$

Clinically tumours of submandibular gland are uncommon and usually present as slow growing, painless swelling. Only $50 \%$ of submandibular swellings are benign. In many cases swelling cannot on clinical examination be differentiated from submandibular lymphadenopathy. ${ }^{3}$

FNAC and core needle biopsy are helpful. FNAC in experienced hands can determine whether the tumour is malignant with sensitivity of around $90 \%$. FNAC can also distinguish primary salivary gland tumour from metastatic disease. ${ }^{1}$

Ultrasound can determine and characterise superficial parotid tumour. It is also frequently used to guide FNA. ${ }^{1}$

CT allows direct, bilateral visualisation and provides information about overall dimensions and tissue invasions. ${ }^{4}$

MRI provides superior soft tissue delineation such as perineural invasion. ${ }^{4}$

The proper treatment for pleomorphic adenoma is its total surgical removal, along with margin of normal salivary tissue that surrounds it. For tumour located in superficial lobe of parotid, which represents the majority, standard surgery is superficial parotidectomy. For small pleomorphic adenoma in submandibular gland, total submandibular gland excision is appropriate but for tumours that are large and project beyond the submandibular gland is best served by suprahyoid neck dissection preserving the marginal mandibular branch, lingual nerve and hypoglossal nerve. In cases of overt malignancy, modified neck dissection is appropriate and may necessitate sacrifice of lingual and hypoglossal nerves. ${ }^{3}$

The recurrence rate of benign mixed tumour depends almost entirely on adequacy of primary excision. Recurrence is very high if tumour is simply enucleated because small inconspicuous nodules attached by threadlike filaments of neoplastic tissue may be present surrounding the main mass. They may have the shape and appearance of lymph node and may be mistaken by surgeon and pathologist for nodal metastasis. If the tumour is enucleated these small remnants will be left behind and provide nidus for recurrence. Most of these recurrences occur during fist 18 months after surgery but others supervene over very long period, 50 years or more and so long term follow up is essential. ${ }^{3}$

\section{REFERENCES:}

1. Cohen EG, patel SG, lin O, et al. Fine needle aspiration biopsy of salivary gland lesions in a selected patient population. Arch otolaryngol Head Neck Surg 2004;130:773

2. Koyunchu M, Sesen T, Akon H, et al(Dec.2003) Comparison of CT and MRI in diagnosis of parotid tumour.

3. McGurk M and RenehanAE(2001) Controversies in the management of salivary gland disease. Oxford University Press, Oxford.

4. Califano J and Eisele DW (1999) Benign salivary gland neoplasm. Otolaryngologic clinics of north America 861-873. 
5. Henriksson G, Westrin KM, Carlsoo B, Silfversward C. Recurrent primary pleomorphic adenomaof salivary gland origin Cancer 1998, 617-620.

6. Chen KTK. Metastasizing pleomorphic adenoma of the salivary gland.cancer 1978, 42:2407-2411.

7. Rosai and Ackerman's Surgical pathology:9th Ed; Major and Minor salivary glands. Pages 878-881.

8. Spiro RH, Hadju SI, Strong EW. Tumours of the submandibular gland. Am J Surg 1976;132:463

9. Malett KJ, Harrison MS. The recurrence of salivary gland tumours. J LaryngolOtol 1971, 85:439-448

10.Patey DH, Thackray AC. The treatment of parotid tumours in the light of pathological study of parotidectomy. Br J Surg 1958, 45;477-487.

\section{PICTURE SPECIMEN}
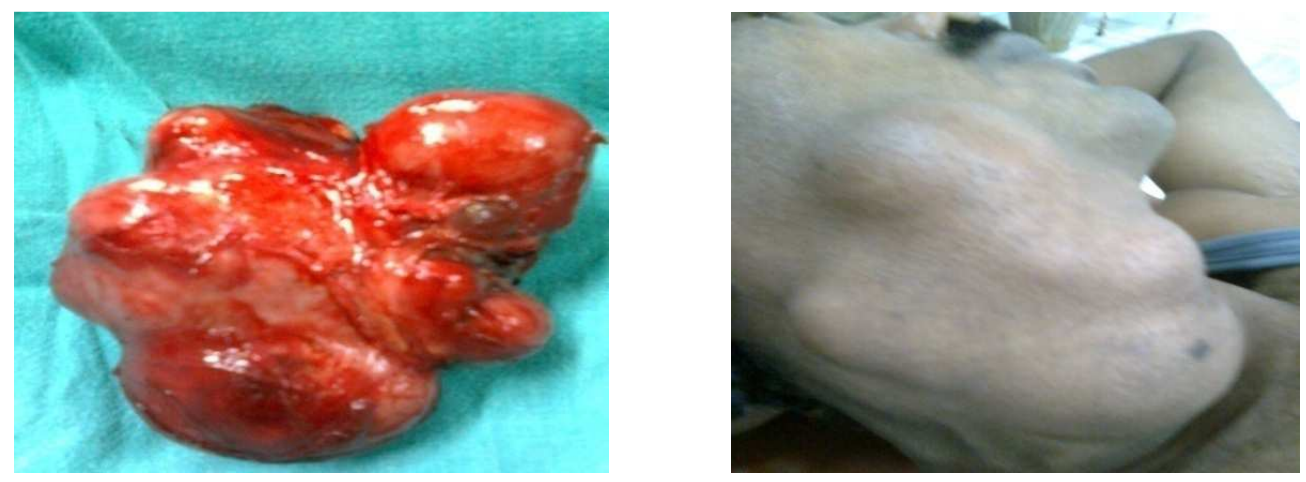